\title{
Obesity and the Warning Trends
}

\section{Saif Al Yaarubi}

Pediatric Endocrinologist, Sultan Qaboos University Hospital, College of Medicine, Oman

\section{The Magnitude of Obesity Epidemic}

The global increase of prevalence of obesity worldwide triggers the alarm of devastating consequences. Worldwide obesity has nearly tripled since 1975 [1]. In 2016, more than 1.9 billion adults, 18 years and older, were overweight, of these over 650 million were obese [1]. Children unfortunately are also affected, 41 million children under the age of 5 were overweight or obese in 2016 and Over 340 million children and adolescents aged 5-19 were overweight or obese in 2016 [1]. This trend has affected almost all countries and does not appear to spare the developing world. The Arabian Gulf countries have ranked consistently in the first ten positions in the world prevalence of obesity.

Below are the countries with the highest prevalence of obesity (in percentage) in the Middle East [2]. The report measures levels of obesity using the Body Mass Index (BMI) which is a person's weight in kilograms divided by the square of height in meters.

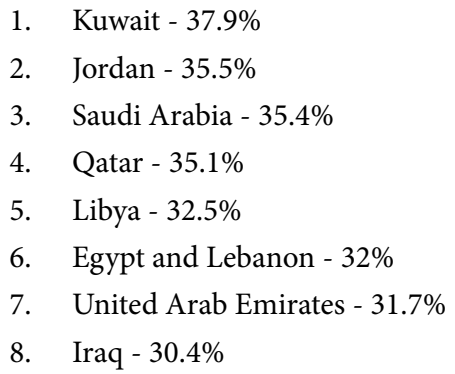

\section{Obesity and Diabetes}

The global increase of obesity prevalence has led to an explosion in the number of diabetic patients, the metabolic syndrome and other complications worldwide.According to a 2016 study from the World Journal of Diabetes, the Middle Eastern and North African region has the second highest rate of increases in diabetes in the world. This could be due to genetic risk, rapid urbanization and lack of exercise [2]. In the Arab world only the number of people with diabetes is projected to increase by $96.2 \%$ by 2035 . The International Diabetes Federation (IDF) estimates from 2013 [3], three countries from the Arabic world are among the top 10 countries worldwide for the prevalence of T2DM; these countries are Saudi Arabia, Kuwait and Qatar. A recent analysis showed a significant increase of $30.5 \%$ in the prevalence of T2DM among children and adolescents aged 10-19 years old in United States from 2001 to 2009 [4]. The figures from the Arab world is more alarming, a recent data from Saudi Arabia reports an agespecific prevalence of 1 per 1000 for T2DM in children less than 18 years old [5], which was similar to the highest prevalence found in specific groups (American Indian and African American) in United States [6]. Unfortunately obese patients have poor prognosis if they develop T2DM and suffer higher rates of microvascular complications and mortality $[7,8]$.

Obesity has also been linked to a wide variety of other medical health problems .This list include cardiovascular diseases (mainly heart disease and stroke) which were one the leading cause of

\section{Publication History:}

Received: December 31, 2018

Accepted: March 06, 2019

Published: March 08, 2019

\section{Keywords:}

Congenital, Hypopituitarism, Partial, Complete, Association, Magnetic resonance imaging (MRI), Saudi Arabia.

death , Nonalcoholic fatty liver disease (NAFLD), and some cancers (including endometrial, breast, ovarian, prostate, liver, gallbladder, kidney, and colon).

\section{Etiology of Obesity}

The global cultural change in the eating behavior, rabid urbanization with the availability of an easy access to food worldwide and the sedentary lifestyle have led to an energy imbalance between calories consumed and calories expended. The widely usage of electronic games and other digital game devices havealso contributed significantly in the raise of obesity prevalence [9]. There are also environmental factors like pollution and the high temperature in certain areas of the world that makes people home restrained and shortens the time available for physical activity.

\section{Future Direction}

There is an international call to unit all efforts to fight the epidemic of obesity .Organizations like the United Nations, World Health Organization, and World Bank emphasize the need to focus on younger generations now to control thenon-communicable diseases associated with obesity in the future $[10,11]$. There should be governmental strategies for healthier communities. These strategies should include all governmental and nongovernmental sectors that are involved in the contribution of the risk factors to develop obesity. Below are some of the initiatives that could be taken to tackle this complicated issue:

1. Media campaign to educate the communities regarding a healthier eating habit and promoting physical activities.

2. Educate students at school and universities regarding living healthy by cutting down the amount of fast food and soft drinks consumed and to a void a sedentary life style.

"Corresponding Author: Dr. Saif Al Yaarubi, Associate Professor, Pediatric Endocrinologist, Sultan Qaboos University Hospital, College of Medicine, Oman; E-mail: alyaarubica@gmail.com

Citation: Yaarubi SA (2019) Obesity and the Warning Trends. Int J Pediatr Neonat Care 5: 150 doi: https://doi.org/10.15344/2455-2364/2019/150

Copyright: (c) 2019 Yaarubi. This is an open-access article distributed under the terms of the Creative Commons Attribution License, which permits unrestricted use, distribution, and reproduction in any medium, provided the original author and source are credited. 
3. Construct the residential areas to include parks and walking areas that are safe and away from pollution.

4. Educate families to restrict the time available for electronic game devises and encourage their children's to be more active.

\section{Competing Interests}

The author declare that there is no competing interests regarding the publication of this article.

\section{Reference}

1. https://www.who.int/news-room/fact-sheets/detail/obesity-andoverweight

2. Abuyassin B, Laher I (2016) Diabetes epidemic sweeping the Arab world. World J Diabetes 7: 165-174.

3. International Diabetes Federation (2013) IDF Diabetes Atlas, 6th edition Brussels, Belgium: International Diabetes Federation.

4. Dabelea D, Mayer-Davis EJ, Saydah S, Imperatore G, Linder B, et al. (2014) Prevalence of type 1 and type 2 diabetes among children and adolescents from 2001 to 2009. JAMA 311: 1778-1786.

5. Al-Rubeaan K (2015) National surveillance for type 1, type 2 diabetes and prediabetes among children and adolescents: a population-based study (SAUDI-DM). J Epidemiol Community Health 69: 1045-1051.

6. Zeitler P, Fu J, Tandon N, Nadeau K, Urakami T, et al. (2014) ISPAD Clinical Practice Consensus Guidelines 2014. Type 2 diabetes in the child and adolescent. Pediatr Diabetes Suppl 20: 26-46.

7. Bonora E, Targher G, Formentini G, Calcaterra F, Lombardi S, et al. (2004) The Metabolic Syndrome is an independent predictor of cardiovascula disease in Type 2 diabetic subjects. Prospective data from the Verona Diabetes Complications Study. Diabet Med 21: 52-58.

8. Logue J, Walker JJ, Leese G, Lindsay R, McKnight J, et al. (2013) Association between BMI measured within a year after diagnosis of type 2 diabetes and mortality. Diabetes Care 36: 887-893.

9. Physical activity recommendations for 5-12 year olds. Australian Government Department of Health and Ageing.

10. New data highlight increases in hypertension, diabetes incidence. World Health Organization.

11. Diabetes prevalence (\% of population ages 20 to 79 ). The World Bank. 